\title{
RESENHAS
}

\author{
REVIEWS
}

\section{RESERVA DO POSSÍVEL, MÍNIMO EXISTENCIAL E DIREITO À SAÚDE: ALGUMAS APROXIMAÇÕES}

Ingo Wolfgang Sarlet \& Mariana Filchtiner Figueiredo.

In: SARLET, Ingo Wolfgang; TIMM, Luciano Benetti (Org.), Direitos

Fundamentais: orçamento e reserva do possível.

Porto Alegre, Livraria do Advogado Editora, 2008.

Daniel Wei Liang Wang(*)

\section{CONTEXTUALIZAÇÃO DA TEMÁTICA E JUSTIFICATIVA DA ESCOLHA DO ARTIGO RESENHADO}

O uso cada vez mais recorrente de ações judiciais para demandar do Estado concretização de direitos sociais tem colocado aos profissionais do Direito (juízes, advogados, promotores, procuradores e juristas) novos desafios em suas atividades, para cujo enfrentamento sua formação, em regra, não os preparou.

Ainda hoje, os cursos de Direito buscam preparar seus alunos para atuar principalmente na proteção de direitos civis e políticos; entender o Direito por uma lógica eminentemente formal; resolver conflitos interindividuais cujos efeitos limitam-se às partes do processo; trabalhar com um padrão de decisão em que o vencedor ganha tudo e o perdedor fica com nada; e lidar com dilemas de justiça comutativa, que busca o reequilíbrio na relação entre indivíduos.

(*) Mestrando em Direito Constitucional pela Faculdade de Direito da Universidade de São Paulo, pesquisador do Programa de Especialização e Educação Continuada em Direito GVLaw da Escola de Direito de São Paulo da Fundação Getúlio Vargas, colaborador da Revista de Direito Sanitário. E-mail:<danielwei_cn@yahoo.com.br>. Recebido em 10.7.08. 
Contudo, essas habilidades mostram-se insuficientes quando se trata de demandas envolvendo direitos sociais. Primeiramente, aplicar uma lógica jurídica eminentemente formal mostra-se pouco útil porque os direitos sociais não se efetivam pelo mero reconhecimento e adjudicação pelo Judiciário, mas por meio de políticas públicas, o que demanda, entre outras coisas, recursos financeiros, planejamento, material, informações empíricas e conhecimentos técnicos específicos de outras áreas que não o Direito. Não há como lidar com todas as dificuldades que surgem com a judicialização dos direitos sociais simplesmente lendo a norma legal e seus comentadores como se eles, por si só, pudessem trazer todas as respostas necessárias ou, então, fazendo um debate teórico sobre princípios abstratos e, em abstrato, sem conhecer a realidade sobre a qual se discute ${ }^{(1)}$.

Além disso, ainda que no caso concreto a disputa seja entre duas partes - Estado e demandante - as implicações das decisões envolvendo direitos sociais provavelmente afetarão diretamente um número muito maior de pessoas. Os direitos sociais são realizados por meio de fundo público sustentado por toda a coletividade, mas usufruíveis por alguns, o que cria necessidade de discussão dos critérios de justiça para permitir ou negar o acesso de alguém ao financiamento público para concretização desses direitos, ou seja, é um debate em torno da justiça distributiva(2). Portanto, os efeitos de uma decisão que concede um direito social para um demandante não se limitam ao Estado que deve gastar um montante de dinheiro e ao cidadão que receberá um determinado bem ou serviço. Mas eles se estendem aos outros membros da coletividade que, dada a realidade da escassez de recursos, poderão deixar de ter algumas de suas necessidades atendidas pelo poder público em razão da escolha alocativa determinada judicialmente ter favorecido aquele que impetrou a ação.

Cabe ressaltar também que, em matéria de direitos sociais, a lógica de decisão do "tudo ou nada" parece não ser a ideal. Questões envolvendo justiça distributiva e políticas públicas, pelas suas características já citadas, talvez devessem ser resolvidas por meio de diálogo, acordos, compromissos e metas ${ }^{(3)}$.

(1) SILVA, Virgílio Afonso da. Taking from the poor to give to the rich: the individualistic enforcement of social rights. Disponível em: <http://www.enelsyn.gr/papers/w13/Paper\%20by\%20Prof.\%20Virgilio \%20Afonso\%20da\%20Silva.pdf>.

(2) Para um estudo mais aprofundado sobre justiça distributiva e comutativa cf. LOPES, José Reinaldo de Lima. Justiça e poder Judiciário ou a virtude confronta a instituição. In: Direitos sociais: teoria e prática. São Paulo: Método, 2006. p. 119-139 e LOPES, José Reinaldo de Lima. Da efetividade dos direitos econômicos sociais e culturais. In: Direitos humanos: visões contemporâneas. Publicação Especial em Comemoração aos 10 anos da Fundação Associação Juízes para Democracia. São Paulo: 2001.

(3) LOPES, José Reinaldo de Lima. Em torno da reserva do possível. In: SARLET, Ingo Wolfgang; TIMM, Luciano Benetti (Orgs.). Direitos fundamentais: orçamento e reserva do possível. Porto Alegre: Livraria do Advogado, 2008. p. 189. 
Neste cenário de descompasso entre a formação dos profissionais do Direito e as novas questões trazidas pela judicialização dos direitos sociais, é bastante compreensível que haja um número cada vez maior de trabalhos jurídicos buscando tratar desse fenômeno que, embora cada vez mais importante dados os seus impactos crescentes para as políticas públicas, até há pouco tempo era analisado de maneira não muito aprofundada.

Dentre os trabalhos recentes que tratam do tema da judicialização dos direitos sociais, destaca-se o livro de Ingo Wolfgang Sarlet e Luciano Benetti Timm, Direitos Fundamentais: orçamento e reserva do possível, de onde escolhemos o artigo "Reserva do possível, mínimo existencial e direito à saúde: algumas aproximações", de autoria de Ingo Wolfgang Sarlet e Mariana Filchtiner Figueiredo, para ser objeto da presente resenha.

A escolha por esse artigo justifica-se por ele tratar consistentemente de dois conceitos que permeiam os outros trabalhos do livro e que aparecem com cada vez mais freqüência nos textos acadêmicos e na jurisprudência sobre judicialização dos direitos sociais: "reserva do possível" e "mínimo existencial". Além de expor o ponto de vista dos autores sobre esses conceitos e de como, na sua análise, esses podem contribuir para resolver alguns dos desafios que a judicialização dos direitos sociais apresenta aos profissionais do direito, pretendemos fazer uma resenha crítica, não com a pretensão de apontar erros, mas de problematizar sobre pontos que, por propiciarem um debate interessantíssimo, talvez mereçam melhor desenvolvimento ${ }^{(4)}$.

\section{EXPOSIÇÃO DOS PRINCIPAIS ARGUMENTOS DO ARTIGO}

\section{Mínimo existencial}

A apresentação deste conceito no texto começa com uma reconstrução de sua origem histórica, que surge com a doutrina alemã e lá ganha força também em âmbito legislativo, administrativo e jurisprudencial a partir da segunda metade do século XX, sendo aceito em diversas decisões da Corte Constitucional alemã ${ }^{(5)}$ e, inclusive, com repercussões no Direito comparado(6).

(4) Os autores em diversas passagens do texto ressaltam que não pretendem esgotar o tema sobre o qual estão tratando. O próprio título do artigo aponta que se pretende apenas fazer "aproximações" sobre os assuntos propostos, o que não poderia ser diferente dada a amplitude do tema. Portanto, não se trata de criticar os autores pela incompletude do texto, o que seria injusto da nossa parte, mas apenas levantar reflexões suscitadas pela leitura do texto e que, sob a ótica da pesquisa do tema da judicialização da saúde, sentimo-nos na obrigação de expor.

(5) SARLET, Ingo Wolfgang; FIGUEIREDO, Mariana Filchtiner. In: SARLET, Ingo Wolfgang; TIMM, Luciano Benetti (Orgs.). op. cit., p. 20.

(6) Id. Ibid., p. 22. 
De acordo com Sarlet e Figueiredo, a garantia do mínimo existencial, que obriga o Estado a prestações que criem condições materiais mínimas para uma vida digna dos seus cidadãos, está fundada (1) no princípio da dignidade humana, pois ela não estaria garantida apenas pela proteção das liberdades individuais, mas precisaria também ser protegida "por um mínimo de segurança social, já que, sem os recursos materiais para uma existência digna, a própria dignidade humana ficaria sacrificada"(7); (2) no direito à vida e à integridade física, que não é apenas a proibição de sua violação, mas pressupõe uma postura ativa na sua proteção e; (3) no direito geral de liberdade, já que a qualidade de pessoa autônoma e responsável não prescinde da garantia de condições mínimas de existência.

Uma vez apresentada a origem do conceito, o texto aponta que não se pode quantificar o mínimo existencial de uma forma única e definitiva, pois ele varia conforme lugar; tempo; padrão socioeconômico vigente; esfera econômica e financeira; expectativas; e necessidades( ${ }^{(8)}$. Faz-se, também, a ressalva de que o mínimo existencial não se limita a garantir a simples sobrevivência física, pois, isso significaria uma vida sem alternativas, o que não promoveria a dignidade humana(9). Portanto, deve-se garantir uma existência digna, que garanta a fruição de todos os direitos fundamentais, o que pode incluir um mínimo existencial sociocultural ${ }^{(10)}$.

Dado que o mínimo existencial não possui uma quantificação única e definitiva, como se determinar o padrão existencial mínimo dentro de uma dada sociedade em um determinado momento? Os autores entendem que cabe ao legislador "a função de dispor sobre a forma da prestação, seu montante, as condições para sua fruição etc.", mas que caberia aos tribunais decidir sobre este padrão existencial mínimo "nos casos de omissão ou desvio de finalidade por parte dos órgãos legiferantes"(11). Em seguida, apresentam a ressalva de que a liberdade de conformação do legislador encontra seu limite "no momento em que o padrão mínimo para assegurar as condições materiais indispensáveis a uma existência digna não for respeitado, isto é, quando o legislador se mantiver aquém desta fronteira".

Enfatizam também que o mínimo existencial, por compreender "todo um conjunto de materiais indispensáveis para assegurar a cada pessoa uma vida condigna", pode ser identificado como o "núcleo essencial dos direitos fundamentais sociais (...) blindado contra toda e qualquer intervenção por parte do Estado e da sociedade ${ }^{(12) "}$.

(7) SARLET, Ingo Wolfgang; FIGUEIREDO, Mariana Filchtiner. op. cit., p. 19.

(8) Id. Ibid., p. 20-21.

(9) Id. Ibid., p. 21.

(10) Id. Ibid., p. 21.

(11) Id. Ibid., p. 22-23.

(12) Id. Ibid., p. 25. 
Entendem, ainda, que mesmo esse "núcleo essencial" dos direitos sociais, que eles equiparam ao mínimo existencial, não é o mesmo para cada direito social e não dispensa a necessária contextualização e interpretação(13). Isso ocorre porque, no seu entendimento, é impossível estabelecer de forma taxativa, peremptória e apriorística, um elenco de "posições subjetivas positivas e negativas" correspondentes ao mínimo existencial(14). O mínimo existencial deve ser avaliado à luz das circunstâncias de cada caso, sem excluir a possibilidade de "inventariar" as conquistas já sedimentadas, o que possibilita a inclusão da educação fundamental, da saúde básica, da assistência aos desamparados e do acesso à justiça dentro de seu conteúdo(15), conforme defende Ana Paula Barcellos, citada no artigo"(16).

\section{Reserva do possível}

Sarlet e Figueiredo avaliam que os direitos sociais, mas não só eles, pressupõem marcadamente uma obrigação positiva - prestações estatais -, ou seja, implicam custos para serem efetivados, o que faz com que tenham uma "dimensão economicamente relevante"(17).

Portanto, os direitos sociais possuem um limite fático à sua efetivação, que está na real existência de meios por parte dos cofres públicos do Estado para cumprir com suas obrigações ${ }^{(18)}$. Além desse limite fático, existe também limitação quanto à possibilidade jurídica do Estado de dispor desses recursos, quando existentes ${ }^{(19)}$. Essas duas limitações formam a chamada "reserva do possível"(20).

Esse conceito teórico foi também criado na doutrina alemã e passou a ganhar força a partir dos anos 1970, sendo, inclusive, reconhecido pelo Tribunal Constitucional Federal da Alemanha, que entendeu também que uma prestação reclamada deve corresponder "àquilo que o indivíduo pode razoavelmente exigir da sociedade"(21).

A partir desses elementos, o texto apresenta uma dimensão tríplice da reserva do possível: (a) efetiva existência de recursos para efetivação dos direitos fundamentais; (b) disponibilidade jurídica de dispor desses recur-

(13) SARLET, Ingo Wolfgang; FIGUEIREDO, Mariana Filchtiner. op. cit., p. 26. O exemplo dessa contextualização e interpretação que os autores consideram necessárias é o do direito à moradia digna, que pode variar conforme as condições climáticas.

(14) Id. Ibid., p. 26.

(15) Id. Ibid., p. 26.

(16) Id. Ibid., p. 23.

(17) Id. Ibid., p. 27.

(18) Id. Ibid., p. 29.

(19) Id. Ibid., p. 29.

(20) Id. Ibid., p. 29.

(21) Id. Ibid., p. 29. 
sos, em função da distribuição de receitas e competências, federativas, orçamentárias, tributárias, administrativas e legislativas; (c) razoabilidade daquilo que está sendo pedido(22).

Segundo os autores, a reserva do possível não impede o poder Judiciário de "zelar pela efetivação dos direitos sociais", mas deve fazê-lo com cautela e responsabilidade, consciente do problema da escassez de recursos. Contudo, argumentam, ela muitas vezes é inaceitavelmente usada como desculpa genérica para não intervenção do Judiciário em matéria de direitos sociais. Portanto, cabe ao poder público o ônus de provar a "falta efetiva de recursos" e de provar que cumpre sua obrigação de aplicá-los eficientemente ${ }^{(23)}$.

Ainda tratando sobre o Poder Judiciário, entendem que a inafastabilidade do controle jurisdicional previsto na Constituição Federal dá aos juízes poder para tutelar qualquer lesão ou ameaça a direito, ainda que decorrentes de "políticas públicas" ou da falta delas, sem ignorar a necessidade de uma "prudente e responsável autolimitação funcional" por parte dos magistrados ${ }^{(24)}$.

\section{Relação entre reserva do possível e mínimo existencial}

Os autores alinham-se com posições que defendem que a reserva do possível deve ser relativizada quando se está no campo do mínimo existencial, uma vez que este cria "direitos subjetivos a prestações", bem como deve ser priorizado nas destinações orçamentárias ${ }^{(25)}$. Quando o mínimo existencial estiver em causa, tem-se um direito subjetivo a prestações que são plenamente exigíveis pela via jurisdicional, devendo prevalecer a vida e a dignidade da pessoa sobre objeções quanto à reserva do possível(26).

Especificamente no caso de demandas judiciais sobre direito à saúde, para que seja compatível com a reserva do possível, o mínimo existencial configurar-se-ia pela comprovação em cada caso da necessidade do que se está pedindo, da inexistência de tratamentos alternativos eficientes e da impossibilidade do pleiteante de prover com recursos próprios sua saúde pessoal(27). Eles partem da interpretação de que os princípios da universalidade e integralidade do sistema de saúde não significam a gratuidade das prestações materiais para todas as pessoas e em qualquer situação(28).

Também ressaltam que não concordam com o posicionamento de que é judicialmente exigível apenas o fornecimento de medicamentos aprova-

(22) SARLET, Ingo Wolfgang; FIGUEIREDO, Mariana Filchtiner. op. cit., p. 30.

(23) Id. Ibid., p. 31-32.

(24) Id. Ibid., p. 36.

(25) Id. Ibid., p. 32-33.

(26) Id. Ibid., p. 37, 43 e 46.

(27) Id. Ibid., p. 44.

(28) Id. Ibid., p. 45. 
dos em protocolos do Ministério da Saúde ou das Secretarias de Saúde estaduais e municipais, podendo a opção técnica do setor governamental ser questionada em algumas hipóteses ${ }^{(29)}$. Tampouco aceitam que o Estado possa ser condenado apenas a fornecer medicamentos e tratamentos previstos nas listas do sistema de saúde, uma vez que estas não dão respostas a todas as demandas existentes, podendo excluir prestações que se relacionam com o mínimo existencial(30).

Por fim, concluem que levar a sério a reserva do possível não pode obstaculizar a plena eficácia do mínimo existencial, cuja proteção deve ocorrer inclusive jurisdicionalmente ${ }^{(31)}$.

\section{ANÁLISE CRÍTICA DO ARTIGO}

Após expor os principais argumentos do artigo, passamos a uma análise crítica que, conforme dito no começo desta resenha, tem por intenção problematizar sobre alguns pontos que possam promover um debate bastante construtivo.

Primeiramente, questionamos a pertinência do conceito "mínimo existencial" no debate jurídico brasileiro a respeito dos direitos sociais e, especificamente, sobre sua justiciabilidade. A construção desse conceito, com fundamentação constitucional decorrente da dignidade humana, do direito à vida e à integridade física, para exigir do Estado prestações que tornem eficazes garantias mínimas de existência para seus cidadãos, faz muito sentido quando se tem uma constituição que não prevê direitos sociais de cunho prestacional, como a alemã. Porém, no caso do Brasil, em que há expressamente um extenso rol de direitos sociais constitucionalizados, parece-nos que não há necessidade dessa construção teórica quando o que se quer com ela criar já está dado de forma explícita.

Ademais, atentar para a dignidade humana é um pressuposto básico, um mandamento constitucional (art. 1을 inc. III). Portanto, em termos de reconhecimento de obrigações positivas do poder público para garantir existência digna do indivíduo, o mínimo existencial talvez pouco agregue, pois a Constituição Federal já consagra isso.

Pode-se dizer que o mínimo existencial tem importância para definir o núcleo essencial desses direitos sociais. Seria, então, uma forma de guiar o intérprete na busca do núcleo essencial desses direitos. Contudo, entendemos que o fato do mínimo existencial ser variável e dependente das circunstâncias coloca em dúvida sua capacidade de servir de referência para definir

(29) SARLET, Ingo Wolfgang; FIGUEIREDO, Mariana Filchtiner. op. cit., p. 45-46

(30) Id. Ibid., p. 47-48.

(31) Id. Ibid., p. 49. 
o núcleo essencial dos direitos sociais. Pois, dizer simplesmente que é aquilo que busca garantir uma vida digna ajuda pouco a resolver casos concretos, já que todo direito fundamental colabora para garantir a dignidade da vida humana. Onde começa e onde termina o núcleo essencial de um direito? Não vemos como o conceito de mínimo existencial pode ser um parâmetro mais sólido para o intérprete a fim de decidir um caso concreto.

Dessa forma, entendemos também que a ideia de mínimo existencial não reforça a garantia ao fundamental dos direitos sociais, pois não cria parâmetros claros nem para a tomada de decisão de legisladores, administradores ou juízes, e tampouco para seu controle social.

Ainda que os autores admitam a impossibilidade de se "quantificar" de forma apriorística, única e definitiva o mínimo existencial, mesmo no caso concreto, tem-se dificuldades não só na definição do que é o mínimo existencial, mas também, para saber quem define o que ele é. No artigo, está afirmado que "a função de dispor sobre a forma da prestação, seu montante, as condições para sua fruição etc." é do legislador e que cabe ao Judiciário controlar a atuação do Legislativo quando ele for omisso ou se desviar de sua finalidade, o que ocorre quando o "padrão mínimo para assegurar as condições materiais indispensáveis a uma existência digna não for respeitado". Ora, mas se ao Legislativo cabe decidir sobre o montante, forma e condição para fruição do mínimo existencial, como pode o Judiciário, e com base em quais critérios, dizer que o legislador atuou de forma errada? Como pode a instituição incumbida para estabelecer os critérios ser criticada com base nesses mesmos critérios?

Pode-se fazer a leitura, como a de Ricardo Lobo Torres, de que o mínimo existencial é "pré-constitucional"(32), como uma espécie de direito natural, e que, portanto, antecede o Estado constitucionalmente instituído e, consequentemente, também o legislador. Mesmo em se aceitando esta tese, existe o problema de decidir quem vai dizer o que é esse mínimo existencial e de onde buscar as referências para ele, além das normas legais. Que poder - Legislativo, Executivo ou Judiciário - e de qual maneira, é capaz de captar o conteúdo desse mínimo existencial para em um caso concreto afirmar que outro poder errou na sua avaliação?

Pensando no problema concreto específico da judicialização do direito à saúde, acredito que seja muito difícil que o conceito de mínimo existencial trabalhado pelos autores possa autorizar o juiz a determinar se a administração ou o legislador errou, ou não, em recusar fornecimento de um determinado medicamento ou tratamento. Quando se trata de direito à saúde, em que se pede medicamento ou tratamento médico, a relação com a vida e a dignidade

(32) TORRES, Ricardo Lobo. Tratado de direito constitucional financeiro e tributário. 3. ed. Rio de Janeiro: Renovar, 2008. v. 5, p. 358. 
da pessoa humana é presente em praticamente todas as situações. Então, tirando os casos aparentemente menos complicados de se resolver, como aqueles envolvendo tratamentos ou medicamentos sem eficácia comprovada ou que possuem alternativas de mesma eficácia e custo menor, os juízes não poderiam considerar questões envolvendo a reserva do possível.

Mesmo o critério de se avaliar a capacidade do pleiteante de custear por conta própria o tratamento ou medicamento pedido, a nosso ver, em poucos casos se justificaria uma não concessão. Isso porque, de acordo com estudos empíricos existentes ${ }^{(33)}$, a maior parte dos gastos com medicamentos concedidos pelo Judiciário vai para custear produtos de alto custo os quais, em regra, não são fornecidos por planos privados de saúde e cujo pagamento direto é inviável para a grande maioria da população ${ }^{(34)}$. Portanto, intuimos que o uso desse critério talvez não atenue tanto os impactos financeiros da judicialização, embora essa seja uma afirmação que carece de fundamentação empírica.

Todos esses critérios sugeridos para avaliar pedidos judiciais em matéria de saúde, no nosso entendimento, não conseguem superar o fato de que mesmo entre o que eles consideram dentro do mínimo existencial - o que seria o judicialmente exigível (ligado ao direito à vida e à dignidade humana, com eficácia cientificamente comprovada, sem alternativas equivalentes e de menor custo, e impossibilidade do paciente custear com recursos próprios o que se pede) - não há recursos suficientes para atender a todos os casos, de forma que escolhas devem ser feitas e, portanto, alguns cidadãos terão suas necessidades preteridas.

Argumentar o contrário seria defender que o sistema público de saúde no Brasil pode dispor para todos os seus cidadãos todos os melhores tratamentos para todos os problemas de saúde existentes, o que é irreal até mesmo para os países mais desenvolvidos. Apenas a título de exemplo, Fabíola Vieira e Octávio Ferraz calcularam que se o sistema público de saúde oferecesse os tratamentos mais recentes disponíveis no mercado para todos os portadores de hepatite viral crônica $\mathrm{C}$ e atrite reumatoide, que juntamente atingem $1 \%$ da população, isso teria como custo $R \$ 99,5$ bilhões, o que seria superior ao gasto total de todas as esferas de governo com o conjunto de ações e serviços de saúde ${ }^{(35)}$. Conseguiria o Estado brasileiro

(33) VIEIRA, Fabiola Sulpino; ZUCCHI, Paola. Distorções causadas pelas ações judiciais à política de medicamentos no Brasil. Revista de Saúde Pública, São Paulo, v. 41, n. 2, p. 214-222, 2007; TERRAZAS, Fernanda. O Poder Judiciário como voz institucional dos pobres: o caso das demandas judiciais por medicamentos. 2007. Dissertação (Mestrado) — Faculdade de Direito, Universidade de São Paulo, São Paulo, 2007.

(34) VIANNA, Sólon Magalhães; NUNES, André; GÓES, Geraldo. Atenção de alta complexidade no SUS: desigualdades no acesso e no financiamento. Projeto Economia da Saúde - Ministério da Saúde/IPEA. Brasília, 2005. v. 1, p. 22.

(35) FERRAZ, Otávio; VIEIRA, Fabíola. Direito à saúde, políticas públicas e desigualdades sociais no Brasil: eqüidade como princípio fundamental. Não publicado. 
garantir o mínimo existencial para esse 1\% da população sem afetar direitos de outras pessoas que dependem de seu serviço?

Além do mais, é preciso olhar não só para quem ganha, mas também para quem perde com determinada forma de alocar recursos. Luiz Roberto Barradas Barata, então Secretário de Saúde do Estado de São Paulo em 2005, afirmou que a geração de gastos não previstos no orçamento, pelo Poder Judiciário, obrigava-o a, entre outras coisas, deixar de incrementar o Programa de Saúde da Família, uma política voltada para atenção básica da população mais carente( ${ }^{(36)}$. Ainda que essa afirmação seja de difícil comprovação, não é irrazoável afirmar que a grande quantidade de recursos da saúde gasta para cumprir as decisões judiciais ${ }^{(37)}$ não pode ser alocada sem afetar outras políticas de saúde que, por sua vez, também protegem o que seria o mínimo existencial de outros cidadãos.

Portanto, talvez seja problemático afirmar que, quando se tratar de mínimo existencial, objeções fundadas na reserva do possível não devem nunca prevalecer. Pois mesmo que se considere estar frente a um caso de mínimo existencial, ainda assim, questões de justiça distributiva e de escoIhas de prioridades políticas públicas ainda estarão presentes.

\section{REFERÊNCIAS BIBLIOGRÁFICAS}

FERRAZ, Otávio; VIEIRA, Fabíola. Direito à saúde, políticas públicas e desigualdades sociais no Brasil: eqüidade como princípio fundamental. Não publicado.

LOPES, José Reinaldo de Lima. Da efetividade dos direitos econômicos sociais e culturais. In: Direitos humanos: visões contemporâneas. Publicação Especial em Comemoração aos 10 anos da Fundação Associação Juízes para Democracia. São Paulo: 2001.

Em torno da reserva do possível. In: SARLET, Ingo Wolfgang; TIMM, Luciano Benetti (Orgs.). Direitos fundamentais: orçamento e reserva do possível. Porto Alegre: Livraria do Advogado, 2008.

Justiça e poder Judiciário ou a virtude confronta a instituição. In: _. Direitos sociais: teoria e prática. São Paulo: Método, 2006.

O ESTADO de S. Paulo, São Paulo, 05 fev. 2005. p. A 22.

(36) O ESTADO de S. Paulo, São Paulo, 05 fev. 2005. p. A 22.

(37) De acordo com o Ministro José Gomes Temporão, os Estados gastam aproximadamente R\$500 milhões de reais para comprar medicamentos ordenados via ações judiciais, cf. TEMPORÃO acusa Justiça de tomar "lugar dos médicos". Folha de S. Paulo, 19 out. 2007. Disponível em: <http:// www1.folha.uol.com.br/folha/cotidiano/ult95u337955.shtml>. Acesso em: 25 nov. 2007. 
SARLET, Ingo Wolfgang; FIGUEIREDO, Mariana Filchtiner. In: SARLET, Ingo Wolfgang; TIMM, Luciano Benetti (Orgs.). Direitos fundamentais: orçamento e reserva do possível. Porto Alegre: Livraria do Advogado, 2008.

SILVA, Virgílio Afonso da. Taking from the poor to give to the rich: the individualistic enforcement of social rights. Disponível em: <http://www.enelsyn.gr/papers/w13/ Paper\%20by\%20Prof.\%20Virgilio\%20Afonso\%20da\%20Silva.pdf>.

TEMPORÃO acusa Justiça de tomar "lugar dos médicos". Folha de S. Paulo, 19 out. 2007. Disponível em: <http://www1.folha.uol.com.br/folha/cotidiano/ ult95u337955.shtml>. Acesso em: 25 nov. 2007.

TERRAZAS, Fernanda. O Poder Judiciário como voz institucional dos pobres: o caso das demandas judiciais por medicamentos. 2007. Dissertação (Mestrado) - Faculdade de Direito, Universidade de São Paulo, São Paulo, 2007.

TORRES, Ricardo Lobo. Tratado de direito constitucional financeiro e tributário. 3. ed. Rio de Janeiro: Renovar, 2008. v. 5.

VIANNA, Sólon Magalhães; NUNES, André; GÓES, Geraldo. Atenção de alta complexidade no SUS: desigualdades no acesso e no financiamento. Projeto Economia da Saúde - Ministério da Saúde/IPEA. Brasília, 2005. v. 1.

VIEIRA, Fabiola Sulpino; ZUCCHI, Paola. Distorções causadas pelas ações judiciais à política de medicamentos no Brasil. Revista de Saúde Pública, São Paulo, v. 41, n. 2, p. 214-222, 2007. 